\title{
Can Upper Airway Surgeries Improve Lower Airway Function ? A Prospective Study
}

\author{
K. A. Arifa ${ }^{1}$ V. G. Nayana ${ }^{1}$ - K. M. $\operatorname{Irfan}^{2}$
}

Received: 14 October 2020/ Accepted: 7 December 2020/Published online: 29 January 2021

(C) Association of Otolaryngologists of India 2021

\begin{abstract}
Deviated nasal septum and turbinate hypertrophy are the most common causes for nasal obstruction, which compromise nasal airflow and increases airway resistance. These conditions can further reduce the airflow to lung, which will affect the lung volume and function subsequently reduces the exercise tolerance. The present study aimed to evaluate the impact of upper airway surgeries like septoplasty and turbinoplasty on lower airway functions using simple tests like spirometry and $6 \mathrm{~min}$ walking test $(6 \mathrm{mWt})$. This research was a prospective study. There were 88 subjects in the study who completed follow up. Spirometry and $6 \mathrm{mWt}$ was performed 1 day before and 1 month after surgery in all subjects. Mean preoperative and postoperative values of spirometry (forced vital capacity (FVC),forced expiratory volume in $1 \mathrm{~s}$ (FEV1), forced expiratory volume in $1 \mathrm{~s} /$ forced vital capacity (FEV1/FVC), peak expiratory flow rate (PEFR) and $6 \mathrm{mWt}$ (systolic blood pressure, diastolic blood pressure, heart rate and oxygen saturation) parameters were compared and analyzed. Percentage of improvement of each parameter was compared with the type of surgery, side of obstruction, age of the patient and duration of symptom. Spirometry showed statistically significant improvement in all 4 parameters after surgery in 86 subjects. $6 \mathrm{mWt}$ showed statistically significant improvement in SBP and $\mathrm{SpO} 2$ and there was no significant improvement in DBP and HR. We also observed that improvement
\end{abstract}

V. G. Nayana

drnayanavg@yenepoya.edu.in

1 Dept of Otorhinolaryngology, Yenepoya Medical College, Derelakkatte, Mangalore, Karnataka, India

2 Department of Pulmonary Medicine, Yenepoya Medical College, Derelakkatte, Mangalore, Karnataka, India in parameters was irrespective of age and duration of symptoms. So this study concludes that airway narrowing nasal diseases can compromise lower airway function.

Keywords Nasal obstruction - Spirometry ·

Exercise tolerance $\cdot$ Airway resistance $\cdot$ Nasal septum

\section{Introduction}

The influence of nasal breathing on pulmonary function was widely studied in the recent past. The nasal cavity is a subsite of the upper airway and any obstruction at that level is called as the upper airway obstruction or extra thoracic obstruction. Chronic nasal obstruction leads to mouth breathing which will compromise the role of the nose in humidifying and warming the inspired air. This can alter the diffusion and viscosity of pulmonary surfactants leading to bronchial constriction [1]. Chronic nasal obstruction also augments the upper airway resistance which will compromise the airflow to the lungs and increase the work of breathing.

Nasal obstruction is one of the most common reasons for frequent outpatient visits in Otorhinolaryngology practice. It can be either due to mucosal factors or anatomical factors. The most common anatomical abnormality is symptomatic Deviated Nasal Septum (DNS). A clinically significant septal deviation is defined as the deviation that amounts to severe obstruction, which is not mitigated by medical therapy [2]. The symptomatic deviated nasal septum is rectified by septoplasty which is a commonly performed surgery in otorhinolaryngology.

Inferior turbinate hypertrophy is another etiology for chronic nasal obstruction. Impaired nasal cycle due to DNS along with inhaled allergen, irritant, and repeated infection 
can lead to persistent turbinate hypertrophy [3]. Medical management like topical corticosteroid, anti-histamine and decongestants will help in the early stage. Once failed, surgical correction is required, like partial inferior turbinectomy [4].

Though nasal and lung pathologies are treated as separate entities, the upper and lower airway can be considered as a single anatomical and functional unit. Subjective improvement of upper airway following nasal surgeries are measured by SNOT 22 and NOSE questionnaire and objective improvement by rhinomanometry and acoustic rhinometry. The lower airway can be measured with spirometry to evaluate lung volume, and lung functions. The 6 min walking test $(6 \mathrm{mWt})$ is used to estimate exercise tolerance. Exercise tolerance is influenced by the level of oxygen in the blood. Mechanical nasal obstruction results in increased resistance to the inspired air which can indirectly influence pulmonary functions and exercise tolerance.

This research aims to evaluate the improvement in pulmonary function and exercise tolerance following septoplasty and turbinate reduction surgery by doing simple tests like spirometry and $6 \mathrm{mWt}$.

\section{Materials and Methodology}

This research was a prospective study done in a tertiary care medical centre over a period of 18 months. This study was conducted after approval from the Institutional Ethics Committee under tenets of the Declaration of Helsinki as per National Ethical Guidelines for Biomedical Research involving human participants of the Indian Council of Medical Research (ICMR), 2017.

Purposive sampling was done. A sample size of 90 was estimated based on a 5\% level of significance and $80 \%$ power with effect size 0.3. 90 subjects, aged more than 18 years, with chronic nasal obstruction secondary to a septal deviation with or without inferior turbinate hypertrophy, were enrolled in the study after getting written informed consent. Subjects with hypertension, coronary artery disease, diabetes mellitus, cerebrovascular infarcts, body mass index more than $30 \mathrm{~kg} / \mathrm{m} 2$ which can impair exercise tolerance, and participants with other nasal pathologies such as allergic rhinitis, chronic rhinosinusitis or nasal polyposis, or any history of previous nasal surgery and cigarette smokers were excluded from the study. Subjects who failed to perform the test were also excluded. Due to Covid-19 pandemic restrictions, 2 subjects failed to report for follow up, hence statistical analysis was done for 88 patients.

Relevant clinical and demographic data were obtained from all subjects. Detailed ENT examination and diagnostic nasal endoscopy were done to confirm the diagnosis. Subjects with significant deviated septum underwent conservative septoplasty. Inferior partial turbinoplasty was done for those with turbinate hypertrophy. After surgery, nasal pack was kept for $24 \mathrm{~h}$ and all subjects were discharged on postoperative day 2. Surgeries were done by a single surgeon using same technique under general anaesthesia, in the same hospital.

Pulmonary function test (PFT) and $6 \mathrm{mWt}$ were performed on all subjects, 1 day before and 1 month after surgery. PFT was performed using Smart pft CO Transfer Machine, Medical Equipment Europe GmbH, Germany. Three trials were done on each subject in an upright sitting position and the best of the 3 trials was recorded. Forced vital capacity (FVC), Forced expiratory volume in $1 \mathrm{~s}$ (FEV1), FEV1/FVC, and Peak expiratory flow rate were measured (PEFR). Mean preoperative and postoperative values were compared. This test was done by the same investigator for all patients.

For $6 \mathrm{mWt}$, subjects were asked to walk for $6 \mathrm{~min}$ on a flat, $30 \mathrm{~m}$ long walking area at room temperature. The physiological parameters including Systolic blood pressure (SBP), diastolic blood pressure (DBP), heart rate, and saturation of peripheral oxygen $(\mathrm{SpO} 2)$ were measured by the primary investigator. Mean pre-operative and post-operative values were compared.

\section{Results}

88 subjects met the inclusion criteria and completed follow up. There were 64 (73\%) men and 24 (27\%) women. Subjects were age-wise categorized into 3 groups; 19-30 years, 31-42 years, and 43-55 years. The majority of the participants, 53 subjects $(60 \%)$ belonged to the lower age group, 25(28\%) were in the second category, and 10 were in the last category. Mean age was 29.9.

All participants presented with nasal obstruction, among that $39(44 \%)$ had isolated left-sided obstruction, $22(25 \%)$ had only right sided obstruction, and 27 (31\%) with bilateral obstruction. Subjects were further divided into 3 groups based on duration of symptoms. 48 (55\%) had complaints from 1 to 5 years, 29 (33\%) had symptoms from 6-10 years, and $11(12 \%)$ had a duration of 11-15 years. The mean duration of symptoms before surgery was 6.47 years. Other significant symptoms were: mouth breathing seen in 80 subjects $(90 \%)$ which was suggestive of severe nasal obstruction, mucoid nasal discharge in $66(75 \%)$, postnasal discharge in $58(66 \%)$, headache in 21(24\%), and epistaxis in 20 subjects(23\%).

Subjects were divided into groups based on the type of surgery they had undergone.

Group A: Septoplasty alone (33 patients; 38\%). 
Group B: Bilateral Turbinoplasty alone (9 patients; $10 \%)$.

Group C: Septoplasty with Bilateral Turbinoplasty (32 patients; $36 \%$ ).

Group D: Septoplasty with Right Turbinoplasty (8 patients; 9\%).

Group E: Septoplasty with Left Turbinoplasty (6 patients; 7\%).

Mean values of preoperative and postoperative $6 \mathrm{mWT}$ parameters including diastolic blood pressure(DBP), systolic blood pressure(SBP), heart rate, and oxygen saturation(SpO2) were documented and compared. Statistical analysis was done using paired T-test.

Mean preoperative and postoperative DBP were $82.93 \pm 4.697 \mathrm{mmHg}$ and $82.77 \pm 4.228 \mathrm{mmHg}$, respectively. Though the postoperative value was less than preoperative value, it was not statistically significant. Mean SBP preoperatively was $132.50+/ 5.851 \mathrm{mmHg}$ and postoperatively was $131.91+15.458 \mathrm{mmHg}$ and the improvement in mean value was statistically significant $(\mathrm{p}=0.047)$. The mean heart rate preoperatively was $80.84 \pm 4.242$ beats per minute and postoperatively was $81.36 \pm 4.242$ beats per minute and the difference was not statistically significant $(\mathrm{p}=0.07)$. Mean $\mathrm{SpO} 2$ preoperative and postoperative were $97.56 \pm 0.786 \%$ and $98.48 \pm 0.546 \%$ respectively and the improvement was statistically significant $(\mathrm{p}=0.00)$. Among these parameters, DBP and heart rate did not show substantial improvement following surgery. The above data is shown in Table 1.

The analysis of the spirometry findings revealed that FEV1, FVC, FEV1/FVC ratio, and PEFR values showed statistically significant improvement when preoperative and postoperative values were compared. The analysis was done using a paired t-test. The same is depicted in Table 2. Mean FVC preoperatively was $3.4158 \pm 0.54129 \mathrm{~L}$ and postoperatively was $3.9048 \pm 0.63782 \mathrm{~L}(\mathrm{p}=0.00)$. Mean FEV1 preoperatively was $2.9357+/ 0.46656 \mathrm{~L}$ and postoperatively was $3.3836 \pm 0.51341 \mathrm{~L}(\mathrm{p}=0.00)$. Mean FEV1/FVC preoperatively was $82.9366+/ 6.91298$ and postoperatively was $85.7776(\mathrm{p}=0.00)$. Mean PEFR values improved from $6.8073 \pm 1.64991$ to
$7.7176 \pm 1.65104$ after surgery, and the difference was statistically significant $(\mathrm{p}=0.00)$. Spirometric parameters showed improvement in all participants except for 2 subjects, whose all four parameters were decreased after surgery.

In our study, we also compared percentage of improvement of each parameters with the type of surgery (Table 3) and side of nasal obstruction (Table 4). Percentage of improvement was calculated using the formula (postoperative value- preoperative value)/postoperative value X100. Statistical analysis was done by the Anova test. Forced Vital Capacity showed statistically significant improvement following surgery in the Group A ( $p=0.025)$, compared to other groups. Comparing the side of nasal obstruction, right-sided nasal obstruction showed statistically significant improvement in forced vital capacity following surgery, compared to the left and bilateral nasal obstruction $(\mathrm{p}=0.031)$. Percentage of improvement of each parameters was compared within the age group categories and symptom duration categories. The statistical analysis was done by Anova test. Results showed no significant improvement between different groups.

\section{Discussion}

Claudius Galenus identified the nose as a respiratory instrument in his work "De usu partium" in the second century. The upper airway plays an important role in the innate and adaptive immune response and protect the lower airways. The upper airway and lower airway share similar anatomical and histological features and diseases of both sites are treated as unified airway disease. The main distinguishing feature between the nose and the lungs is that upper airway obstruction is mainly caused by dilatation of blood vessels and oedema, whereas the lower airway obstruction is by contraction of smooth muscle [5]. This research aims to study the impact of upper airway obstruction on lower airways.

Though deviated nasal septum is prevalent in $60-90 \%$ of the population, it is symptomatic only in a very small group [6]. This study included 88 participants and showed a male

Table 1 Comparison of $6 \mathrm{mWt}$ parameters pre and postoperatively

\begin{tabular}{llll}
\hline Parameters measured & Mean Preoperative value & Mean postoperative value & $p$ Value \\
\hline Heart rate & $80.84+/-4.242$ & $81.36+/-4.242$ & 0.79 \\
DBP & $82.93+/-4.697$ & $82.77+/-4.228$ & 0.524 \\
SBP & $132.50+/ 5.851$ & $131.91+/ 5.458$ & 0.047 \\
SPO2 & $97.56+/-0.786$ & $98.48+/-0.546$ & 0.00 \\
\hline
\end{tabular}


Table 2 Comparison of preoperative and postoperative Pulmonary function tests finding

\begin{tabular}{llll}
\hline Parameter & Preoperative Mean \pm SD & Postoperative Mean \pm SD & $p$ value \\
\hline FEV1 & $2.9357+/ 0.46656$ & $3.3836+/-0.51341$ & 0.00 \\
FVC & $3.4158+/-0.54129$ & $3.9048+/-0.63782$ & 0.00 \\
FEV1/FVC & $82.9366+/ 6.91298$ & $85.7776+/-5.09773$ & 0.00 \\
PEFR & $6.8073+/-1.64991$ & $7.7176+/ 1.65104$ & 0.00 \\
\hline
\end{tabular}

predominance of $73 \%$ and the majority $(60 \%)$ belonged to the third decade, which is comparable to other studies [7].

All patients presented with nasal obstruction and $80 \%$ of them had mouth breathing, which was suggestive of severe obstruction. Nasal obstruction secondary to the deviated nasal septum and turbinate hypertrophy was identified as a risk factor for sleep disorders by Mandour et al. [8] and they observed that polysomnography parameters improved following nasal surgeries in addition to improvement in the pulmonary function tests. Morinaga et al. [9] found that nasal surgeries improves apnoea -hypopnoea index besides nocturnal oxygenation in patients with sleep apnoea.

In our study, the mean duration of symptoms was 6.57 years and the majority presented within the first 5 years. Mouth breathing secondary to chronic nasal obstruction can lead to upper airway collapse due to habitual jaw opening, which may not revert to normal even after surgery [10]. They concluded that early intervention is mandatory for the good postoperative outcome. With increasing degrees of nasal obstruction, pulmonary resistance increases, and compliance decreases [11]. Contrary to the above findings, we found that improvement in spirometry and $6 \mathrm{mWt}$ parameters were not influenced by the duration of symptoms. When percentage of improvement of each parameter was compared within age groups we found that it was not statistically significant. We observed that lower airway function improves irrespective of the age of the patient or duration of symptoms.

47 out of 90 patients in this research had left-sided nasal obstruction which is similar to other studies reported in literature [12]. On the other hand, following surgery, right sided obstruction showed a significant improvement compared to left side. This improvement was observed in a single parameter (FVC) only.

Nasal aerodynamics plays an important role in tissue oxygenation during exercise. An increase in nasal resistance reduces the tissue oxygenation and consequently reduces exercise tolerance. $6 \mathrm{mWt}$ is one of the best tools of analysis for the standardization of physical activity with different treatments that affect the oxygenation, airflow variations, oxidative distress controlling capacity, and improvement in muscle activity. $6 \mathrm{mWt}$ is performed as a submaximal cardiovascular endurance test which is one of the parameters to assess physical fitness [13]. This is used to determine the exercise tolerance in patients with pulmonary failure and has been used in chronic lung disease, cardiovascular and neurological disorders.

In the present study, 2 parameters (SBP and Spo2) showed statistically significant improvement while 2 parameters (HR and DBP) did not show statistically significant improvement. Significant improvement in oxygen saturation can be explained by the improved oxygenation of the lung after removing the extrathoracic obstruction. And the increase in heart rate can be explained by the increased exercise capacity following surgery. BorghiSilva et al. [14] studied the effect of physical training on exercise tolerance and observed that heart rate on week 6 and 12 is more than the baseline value, the increase in rate was explained by the improvement in exercise tolerance and increased physical activity. In our study though the difference in mean diastolic BP was not statistically significant, the mean BP showed minimal improvement following surgery $(82.77+/-4.228)$ when compared to the preoperative value $(82.93+/-4.697)$.

Akinoğlu et al. [15] studied the effect of septoplasty on the physical fitness level in 17 patients. Physical fitness was measured using parameters including $6 \mathrm{mWt}$, muscle strength tests, muscle endurance tests, flexibility tests, agility tests, speed tests, and balance tests. The study observed significant improvement in 6 min walking distance following septoplasty. Boas et al. [16] did a study to compare the physical performance in children with mouth and nasal breathing and it was found that children with chronic mouth breathing had poor performance when compared to the healthy controls (nose breathers). This concludes that physical performance and fitness measuring parameters are influenced by lung function.

As the nasal airway form $50 \%$ of total airway resistance, any mechanical obstruction in upper airway obstruction can increase the total airway resistance. There are few studies in the literature observing the positive effect of nasal surgeries on lower airways. Karuthedath et al. [17] found that pulmonary function test improved significantly following endoscopic sinus surgery in 30 patients with chronic rhinosinusitis. Karaman et al. [18] observed significant improvement in all spirometry parameters following septoplasty except for forced expiratory volume. Extrathoracic influence of nasal surgeries on lung function 
Table 3 : Comparison of spirometry and $6 \mathrm{mWt}$ parameters with the type of surgery

\begin{tabular}{|c|c|c|c|c|c|c|c|}
\hline \multirow[t]{2}{*}{ Parameters } & \multirow[t]{2}{*}{ Group } & \multirow[t]{2}{*}{ Number } & \multirow[t]{2}{*}{ Mean } & \multirow{2}{*}{$\begin{array}{l}\text { Standard } \\
\text { deviation }\end{array}$} & \multicolumn{2}{|c|}{$95 \%$ confidence interval for mean } & \multirow[t]{2}{*}{$p$ value } \\
\hline & & & & & Lower bound & Upper bound & \\
\hline \multirow[t]{6}{*}{ FVC percentage of improvement } & Group A & 33 & 14.2913 & 8.24472 & 11.3678 & 17.2147 & \multirow[t]{6}{*}{0.025} \\
\hline & Group B & 9 & 12.6218 & 8.58278 & 6.0245 & 19.2192 & \\
\hline & Group C & 32 & 8.5454 & 8.14673 & 5.6082 & 11.4826 & \\
\hline & Group D & 8 & 11.5263 & 7.43671 & 5.3090 & 17.7435 & \\
\hline & Group E & 6 & 18.0788 & 7.52662 & 10.1801 & 25.9775 & \\
\hline & Total & 88 & 12.0380 & 8.49229 & 10.2387 & 13.8373 & \\
\hline \multirow[t]{6}{*}{ FEV1 percentage of improvement } & Group A & 33 & 14.1162 & 9.12643 & 10.8801 & 17.3523 & \multirow[t]{6}{*}{0.084} \\
\hline & Group B & 9 & 13.9057 & 7.82590 & 7.8902 & 19.9213 & \\
\hline & Group C & 32 & 9.8165 & 7.65401 & 7.0570 & 12.5761 & \\
\hline & Group D & 8 & 15.7903 & 7.12462 & 9.8340 & 21.7467 & \\
\hline & Group E & 6 & 17.7242 & 6.43250 & 10.9737 & 24.4747 & \\
\hline & Total & 88 & 12.9294 & 8.37495 & 11.1549 & 14.7039 & \\
\hline \multirow{6}{*}{$\begin{array}{l}\text { FEV1/FVC percentage } \\
\text { of improvement }\end{array}$} & Group A & 33 & 4.8039 & 8.13465 & 1.9195 & 7.6884 & \multirow[t]{6}{*}{0.222} \\
\hline & Group B & 9 & 3.2606 & 11.75216 & -5.7729 & 12.2941 & \\
\hline & Group C & 32 & 1.2285 & 7.29713 & -1.4024 & 3.8594 & \\
\hline & Group D & 8 & 6.6254 & 7.27770 & 0.5411 & 12.7098 & \\
\hline & Group E & 6 & -0.7804 & 9.08412 & -10.3136 & 8.7528 & \\
\hline & Total & 88 & 3.1308 & 8.34203 & 1.3633 & 4.8983 & \\
\hline \multirow{6}{*}{$\begin{array}{l}\text { PEFR percentage } \\
\text { of improvement }\end{array}$} & Group A & 33 & 12.2030 & 10.67500 & 8.4178 & 15.9882 & \multirow[t]{6}{*}{0.804} \\
\hline & Group B & 9 & 12.3251 & 5.83214 & 7.8421 & 16.8081 & \\
\hline & Group C & 32 & 10.4636 & 10.59926 & 6.6422 & 14.2851 & \\
\hline & Group D & 8 & 15.2585 & 11.72508 & 5.4561 & 25.0609 & \\
\hline & Group E & 6 & 12.7625 & 4.25657 & 8.2955 & 17.2295 & \\
\hline & Total & 88 & 11.8989 & 9.95373 & 9.7899 & 14.0079 & \\
\hline SBP & Group A & 33 & -0.6179 & 2.27000 & -1.4228 & 0.1870 & \multirow[t]{6}{*}{0.638} \\
\hline \multirow[t]{5}{*}{ Percentage of improvement } & Group B & 9 & -0.0353 & 2.53157 & -1.9812 & 1.9107 & \\
\hline & Group C & 32 & -0.3302 & 1.90426 & -1.0168 & 0.3563 & \\
\hline & Group D & 8 & -1.3217 & 2.21544 & -3.1738 & 0.5305 & \\
\hline & Group E & 6 & 0.2391 & 2.16784 & -2.0359 & 2.5141 & \\
\hline & Total & 88 & -0.4592 & 2.13963 & -0.9126 & -0.0059 & \\
\hline \multirow[t]{6}{*}{ DBP percentage of improvement } & Group A & 33 & -0.0734 & 2.87129 & -1.0915 & 0.9447 & \multirow[t]{6}{*}{0.218} \\
\hline & Group B & 9 & 1.0265 & 3.17445 & -1.4136 & 3.4666 & \\
\hline & Group C & 32 & -0.1456 & 2.63176 & -1.0945 & 0.8032 & \\
\hline & Group D & 8 & -2.1629 & 1.57499 & -3.4796 & -0.8461 & \\
\hline & Group E & 6 & -0.4346 & 3.53452 & -4.1439 & 3.2746 & \\
\hline & Total & 88 & -0.2018 & 2.80453 & -0.7960 & 0.3925 & \\
\hline \multirow[t]{6}{*}{ HR percentage of improvement } & Group A & 33 & 0.6454 & 3.15051 & -0.4717 & 1.7625 & \multirow[t]{6}{*}{0.675} \\
\hline & Group B & 9 & 0.2271 & 3.07719 & -2.1383 & 2.5924 & \\
\hline & Group C & 32 & 0.9385 & 3.31356 & -.2562 & 2.1331 & \\
\hline & Group D & 8 & 0.8745 & 4.47819 & -2.8693 & 4.6184 & \\
\hline & Group E & 6 & -1.2875 & 4.11868 & -5.6098 & 3.0348 & \\
\hline & Total & 88 & 0.5982 & 3.36634 & -0.1150 & 1.3115 & \\
\hline
\end{tabular}


Table 3 continued

\begin{tabular}{llllccc}
\hline Parameters & Group & Number & Mean & $\begin{array}{l}\text { Standard } \\
\text { deviation }\end{array}$ & & 95\% confidence interval for mean \\
\cline { 5 - 7 } & & & & & Lower bound & Upper bound \\
\hline $\begin{array}{c}\text { SPO2 percentage } \\
\text { of improvement }\end{array}$ & Group A & 33 & 0.9217 & .73255 & 0.6620 & 1.1815 \\
& Group B & 9 & 0.9036 & .79387 & 0.2934 & 1.5138 \\
& Group C & 32 & 1.0774 & .72528 & 0.8159 & 1.3389 \\
& Group D & 8 & 0.6365 & 0.75847 & 0.0024 & 1.2706 \\
& Group E & 6 & 6734 & 0.82474 & -0.1921 & 1.5389 \\
& Total & 88 & 0.9336 & 0.74074 & 0.7767 & 1.0906 \\
\hline
\end{tabular}

Table 4 Comparison of spirometry and $6 \mathrm{mWt}$ parameters with the side of obstruction

\begin{tabular}{|c|c|c|c|c|c|c|c|}
\hline \multirow[t]{2}{*}{ Parameters } & \multirow[t]{2}{*}{ Group } & \multirow[t]{2}{*}{ Number } & \multirow[t]{2}{*}{ Mean } & \multirow[t]{2}{*}{ Standard deviation } & \multicolumn{2}{|c|}{$95 \%$ confidence interval for mean } & \multirow[t]{2}{*}{$p$ value } \\
\hline & & & & & Lower bound & Upper bound & \\
\hline \multirow[t]{4}{*}{ FVC } & Right & 22 & 15.3720 & 9.64986 & 11.0935 & 19.6505 & 0.031 \\
\hline & Left & 39 & 9.6099 & 7.80838 & 7.0787 & 12.1411 & \\
\hline & Bilateral & 27 & 12.8286 & 7.62234 & 9.8133 & 15.8439 & \\
\hline & Total & 88 & 12.0380 & 8.49229 & 10.2387 & 13.8373 & \\
\hline \multirow[t]{4}{*}{ FEV1 } & Right & 22 & 14.8784 & 10.31273 & 10.3060 & 19.4508 & 0.200 \\
\hline & Left & 39 & 11.1814 & 7.58719 & 8.7219 & 13.6408 & \\
\hline & Bilateral & 27 & 13.8662 & 7.48032 & 10.9071 & 16.8253 & \\
\hline & Total & 88 & 12.9294 & 8.37495 & 11.1549 & 14.7039 & \\
\hline \multirow[t]{4}{*}{ FEV1/FVC } & Right & 22 & 2.5340 & 8.90433 & -1.4139 & 6.4820 & 0.917 \\
\hline & Left & 39 & 3.4703 & 7.68315 & 0.9797 & 5.9609 & \\
\hline & Bilateral & 27 & 3.1266 & 9.05912 & -0.4571 & 6.7103 & \\
\hline & Total & 88 & 3.1308 & 8.34203 & 1.3633 & 4.8983 & \\
\hline \multirow[t]{4}{*}{ PEFR } & Right & 22 & 13.4537 & 9.54527 & 9.2216 & 17.6859 & 0.685 \\
\hline & Left & 39 & 11.6174 & 10.67684 & 8.1563 & 15.0784 & \\
\hline & Bilateral & 27 & 11.0387 & 9.40184 & 7.3195 & 14.7580 & \\
\hline & Total & 88 & 11.8989 & 9.95373 & 9.7899 & 14.0079 & \\
\hline \multirow[t]{4}{*}{ SBP } & Right & 22 & -0.5045 & 2.30103 & -1.5248 & 0.5157 & 0.993 \\
\hline & Left & 39 & -0.4481 & 2.07292 & -1.1200 & 0.2239 & \\
\hline & Bilateral & 27 & -0.4384 & 2.18166 & -1.3015 & 0.4246 & \\
\hline & Total & 88 & -0.4592 & 2.13963 & -0.9126 & -0.0059 & \\
\hline \multirow[t]{4}{*}{ DBP } & Right & 22 & -0.3175 & 2.73803 & -1.5315 & 0.8964 & 0.705 \\
\hline & Left & 39 & -0.3968 & 2.73923 & -1.2847 & 0.4912 & \\
\hline & Bilateral & 27 & 0.1743 & 3.01364 & -1.0179 & 1.3664 & \\
\hline & Total & 88 & -0.2018 & 2.80453 & -0.7960 & 0.3925 & \\
\hline \multirow[t]{4}{*}{ HR } & Right & 22 & 0.9300 & 3.55270 & -0.6452 & 2.5052 & 0.731 \\
\hline & Left & 39 & 0.2823 & 3.02587 & -0.6986 & 1.2632 & \\
\hline & Bilateral & 27 & 0.7842 & 3.75028 & -0.6994 & 2.2678 & \\
\hline & Total & 88 & 0.5982 & 3.36634 & -0.1150 & 1.3115 & \\
\hline \multirow[t]{4}{*}{$\mathrm{SPO} 2$} & Right & 22 & 1.1080 & 0.69416 & 0.8002 & 1.4158 & 0.294 \\
\hline & Left & 39 & 0.8058 & 0.74169 & 0.5654 & 1.0462 & \\
\hline & Bilateral & 27 & 0.9761 & 0.76857 & 0.6721 & 1.2802 & \\
\hline & Total & 88 & 0.9336 & 0.74074 & 0.7767 & 1.0906 & \\
\hline
\end{tabular}


was studied by Tuzuner et al. [19] and they observed spirometry and $6 \mathrm{mWt}$ improved significantly following surgery.

Nasal septal deviation results in impaired mucociliary clearance in both cavities. Along with nasal obstruction, the inhaled air current is trapped in a restricted area of the mucosa, where there is deviated septum. There is increased viscosity of mucus due to excess local evaporation, which indirectly affects the ciliary action [20]. The impaired ciliary function and mechanical obstruction can leads to repeated rhinosinusitis due to reduced drainage of secretions. This results in the synthesis of inflammatory cytokines and reactive oxygen species and free radicals which can impair pulmonary functions [21].

Loehrl et al. [22] found that there was a subjective and objective improvement in asthma with reduced use of bronchodilators following nasal surgery in subjects with coexisting chronic rhinosinusitis. This shows that patients with coexisting lung and sinonasal disease may benefit from early surgical intervention.

The primary objective of this research was to study the effect of nasal surgeries on pulmonary function tests and exercise tolerance in healthy subjects. In this study we observed a significant improvement in lung volume, lung function and exercise tolerance following nasal surgery. This study concludes that upper airway disease can compromise lower airway function by increasing the total airway resistance, impairing nasal mucociliary clearance leading to recurrent infections and by causing mechanical obstruction to the drainage of nasal secretions. We observed significant improvement in spirometric parameters in $86 / 88$ subjects, following surgery. This study proves that widening of the nasal cavity following surgery has a positive impact on lower airways in individuals without any lung pathology and chronic sinonasal diseases. This study also highlights that improvement was irrespective of duration of symptoms or age of subjects.

Acknowledgements Department of otorhinolaryngology.

\section{References}

1. Hira HS, Singh H (1994) Assessment of upper airway obstruction by pulmonary function testing. J Assoc Phys India 42(7):531-534

2. Sedaghat AR, Busaba NY, Cunningham MJ, Kieff DA (2013) Clinical assessment is an accurate predictor of which patients will need septoplasty. Laryngoscope 123(1):48-52

3. Hanif J, Jawad SS, Eccles R (2000) The nasal cycle in health and disease. Clin Otolaryngol Allied Sci 25(6):461-467

4. Wight RG, Jones AS, Beckingham E (1990) Trimming of the inferior turbinates: a prospective long-term study. Clin Otolaryngol Allied Sci 15(4):347-350

5. Licari A, Castagnoli R, Denicolò CF, Rossini L, Marseglia A, Marseglia GL (2017) The Nose and the Lung: United Airway Disease? Front Pediatr 5:44
6. Soboczyński A, Skuratowicz A, Grzegorowski M (1992) Nasal septum deviation in newborns. Acta Otorhinolaryngol Belg 46(3):263-265

7. Rehman A, Hamid S, Ahmad M, Rashid AF (2012) A Prospective Study of Nasal Septal Deformities in Kashmiri Population Attending a Tertiary Care Hospital. Int J Otorhinolaryngol Head Neck Surg 1(3):77-84

8. Mandour YMH, Abo Youssef SM, Moussa HH (2019) Polysomnographic and pulmonary function changes in patients with sleep problems after septoplasty with turbinectomy. Am J Otolaryngol 40(2):187-190

9. Morinaga M, Nakata S, Yasuma F, Noda A, Yagi H, Tagaya M, Sugiura M, Teranishi M, Nakashima T (2009) Pharyngeal morphology: a determinant of successful nasal surgery for sleep apnea. Laryngoscope 119(5):1011-1016

10. Meurice JC, Marc I, Carrier G, Sériès F (1996) Effects of mouth opening on upper airway collapsibility in normal sleeping subjects. Am J Respir Crit Care Med 153(1):255-259

11. Ogura JH (1970) Physiologic relationships of the upper and lower airways. Ann Otol Rhinol Laryngol 79(3):495-498

12. Amer S, Abdullah D, Ammar M (2010) Assessment of nasal septal deformities by anterior rhinoscopy and nasal endoscopy. Tikrit Med J 16(1):14-20

13. Ozkececi G, Akci O, Bucak A, Ulu S, Yalım Z, Aycicek A, Onrat E, Avsar A (2016) The effect of septoplasty on pulmonary artery pressure and right ventricular function in nasal septum deviation. Eur Arch Otorhinolaryngol 273(11):3747-3752

14. Borghi-Silva A, Mendes RG, Trimer R, Oliveira CR, Fregonezi GA, Resqueti VR et al (2015) Potential effect of 6 versus 12-weeks of physical training on cardiac autonomic function and exercise capacity in chronic obstructive pulmonary disease. Eur J Phys Rehabil Med 51(2):211-221

15. Akinoğlu B, Mutlu M, Kocahan T (2017) Effect of septoplasty on functional outcomes and physical fitness level. Med J Islamic World Acad Sci 25(3):67-71

16. Boas AP, Marson FA, Ribeiro MA, Sakano E, Conti PB, Toro $\mathrm{AD}$, Ribeiro JD (2013) Walk test and school performance in mouth-breathing children. Braz J Otorhinolaryngol 79(2):212-218

17. Karuthedath S, Singh I, Chadha S (2014) Impact of Functional Endoscopic Sinus Surgery on the Pulmonary Function of Patients with Chronic Rhinosinusitis: A Prospective Study. Indian J Otolaryngol Head Neck Surg 66(4):441-448

18. Karaman M, Tek A, Tuncel A, Erdem HT (2011) Evaluation of pa $\neg$ tients with septal deviation using respiratory function tests before and after septoplasty. Kulak Burun Bogaz Bas Boyun Cerrahi Derg 19(1):1-5

19. Tuzuner A, Bilgin G, Demirci S, Yuce GD, Acikgoz C, Samim EE (2016) Improvement of Pulmonary Functions Following Septoplasty: How Are Lower Airways Affected? Clin Exp Otorhinolaryngol 9(1):51-55

20. Ulusoy B, Arbag H, Sari O, Yöndemli F (2007) Evaluation of the effects of nasal septal deviation and its surgery on nasal mucociliary clearance in both nasal cavities. Am J Rhinol 21(2):180-183

21. Corren J (1997) Allergic rhinitis and asthma: how important is the link? J Allergy Clin Immunol 99(2):S781-S786

22. Loehrl TA, Ferre RM, Smith TL (2006) Long-term asthma outcomes after endoscopic sinus surgery in aspirin triad patients. Am J otolaryngol 27(3):154-160

Publisher's Note Springer Nature remains neutral with regard to jurisdictional claims in published maps and institutional affiliations. 